\section{Interspecific Hybrid Verification of Rosa with Isozymes}

\author{
Young-ju Kim ${ }^{1}$ and David H. Byrne ${ }^{2}$ \\ Department of Horticultural Sciences, Texas A\&MUniversity, College Station, \\ TX 77843-2133
}

Additional index words. electrophoresis, malate dehydrogenase, acid phosphatase, phosphoglucose isomerase

\begin{abstract}
The hybrid origin of 23 rose (Rosa spp.) accessions was examined with three isozymes: acid phosphatase (E.C.3.1.3.2), malate dehydrogenase (E.C.1.1.1.37), and phosphoglucose isomerase (E.C.5.3.1.9). All three isozymes were useful for interspecific hybrid verification. This procedure was effective if the putative parents were known and differed in isozyme phenotype. To verify the origin of hybrid species or cultivars with hybrid origins, isozymes were useful but limited by the number of generations since the original hybridization and the number of accessions of the putative parental species assayed.
\end{abstract}

Most commercial roses (Rosa spp.) are tetraploids, whereas about two-thirds of the rose species are diploid. Throughout the breeding history of roses, interspecific hybrids within diploids and tetraploids, and between the two common ploidy levels, have been used extensively. The rose breeding program at Texas A\&M Univ. has an objective of developing disease-resistant rose germplasm that can be hybridized with commercial tetraploid germplasm. Because the best known resistance to black spot [Diplocarpon rosae (Lib.) Wolf] is found in the diploid species, the breeding approach needs to effectively introduce diploid traits into tetraploid germplasm. One approach to overcome this challenge is to create amphidiploids by crossing diploid species from various taxonomic sections and subsequently doubling the chromosome number of the sterile interspecific hybrid to yield a fertile amphidiploid.

In this type of breeding effort, accurate verification of the origin of seedlings is needed. Isozymes have been used to verify intraspecific and interspecific hybrid origin in a wide range of crop species (Byrne and Littleton, 1989; Parfitt et al., 1985). Studies with roses, either using isozymes, RFLPs, RAPDs, or mini- and micro-satellite probes have examined a limited number of commercial cultivars (Hubbard et al., 1992; Kuhns and Fretz, 1978; Torres et al, 1993; Vainstein and Ben-Meir, 1994), except for a study using peroxidase isozymes to identify rare species and hybrids (Yoneda et al., 1993). More recently, isozyme polymorphisms for four isozymes in 46 rose species were described; three of the four

Received for publication 2 Oct. 1995. Accepted for publication 11 July 1996 . The cost of publishing this paper was defrayed in part by the payment of page charges. Under postal regulations, this paper therefore must be hereby marked advertisement solely to indicate this fact.

${ }^{1}$ Graduate Student. Current address: Sinwoo Apt. 401-1, Moonchon Juyuk, Ilsan 411-370, Republic of Korea.

${ }^{2}$ Associate Professor isozymes used appeared codominantly inherited and useful for hybrid verification (Kim, 1994).

This study evaluates the use of three polymorphic isozymes to confirm the interspecific origin of 23 putative rose hybrids.

\section{Materials and Methods}

Twenty-three putative hybrid rose genotypes, including 15 rose interspecific hybrids, three species thought to be interspecific hybrids, and five named cultivars and their putative parental species ( 1 to 11 accessions of 12 species), were assayed for acid phosphatase (ACP), malate dehydrogenase (MDH), and phosphoglucose isomerase (PGI) (Table 1). Sample preparation and electrophoretic procedures were modified from Byrne and Littleton (1988) as follows: samples were prepared with $150 \mathrm{mg}$ of diced leaf tissue, $0.1 \mathrm{~g}$ of polyvinylpolypyrrolidone (PVPP), and $2 \mathrm{~mL}$ of extraction buffer $(100 \mathrm{~mL}$ Na-phosphate buffer, $\mathrm{pH} 7.3 ; 2.5 \mathrm{~g}$ polyvinylpyrrolidone (PVP40), $1 \mathrm{~mL}$ mercaptoethanol, and $0.25 \mathrm{~mL}$ Tween 80). ACP and MDH were assayed on a morpholine citrate system ( $\mathrm{pH}$ 6.1) and PGI on histidine ( $\mathrm{pH}$ 5.7) and lithium borate ( $\mathrm{pH} 8.3$ ) systems. The bands were numbered starting with the fastest migrating band. The putative hybrids and their parental species were run at least twice to confirm their banding patterns.

\section{Results and Discussion}

Most species had predominantly onebanded phenotypes for all enzyme loci (Table 1). The exceptions with frequent multiplebanded patterns were $R$. chinensis Jacq. (MDH1), $R$. moschata Herrm. (PGI-2), R. rugosa Thunb. (MDH-2), and R. setigera Michx.(PGI2).

ACP had five bands. The least common was A4 found only in R. laevigata Michx. and the most common was A2, found in six of the 12 species examined (Fig. 1, Table 1). Most species had the MDH-1 band M3 (Fig. 2, Table 1). The major exception was $R$. chinensis in which the triplets (M1, M2, M3 and M3, M4, M5) were most common. All but one of the 11 R. rugosa accessions contained only M3. MDH-2 was more variable than MDH-1 with nine species having M7, two with M9, and one with M11. Rosa rugosa was variable for this allozyme and showed a total of five bands (M7, M8, M9, M10, M11) in various combinations, although the most common band was M9. PGI-1 was monomorphic (I3) (Fig. 3, Table 1). The most common band for PGI-2 among the species was I7. Seven of the 12 species contained only $\mathrm{I} 7$, one had only $\mathrm{I} 9(R$. laevigata), whereas the rest had several banding patterns.

All the numbered hybrids created by the rose breeding program were consistent with their recorded parentage, except for 19-51 (Table 1). Morphologically, 19-51 does not appear to be a $R$. wichuraiana Crép. hybrid. The isozyme data indicate that neither $R$. wichuraiana nor $R$. laevigata were parents of 19-51 because it lacks both parental ACP bands. Given a ACP phenotype of A2, the potential parents are $R$. banksiae Ait., $R$. brunonii Lindl., $R$. chinensis, $R$. ×odorata (Andr.) Sweet., $R$. rugosa, and $R$. setigera (Table 1). All of these species are consistent with the MDH phenotype of the hybrid, although $R$. rugosa parentage can be ruled out due to the lack of rugose leaves and dense prickles that are typical of $R$. rugosa hybrids. The glossy leaves indicates $R$. banksiae is one of the parents, and since 19-51 has a PGI-2 phenotype of $\mathrm{I} 7, \mathrm{I} 8, \mathrm{I} 9, R$. brunonii or $R$. setigera is the other parent because these have the I9 band.

None of the three rose species of interspecific origins are completely consistent with their presumed parentage (Table 1). Rosa $\times$ fortuniana Ait. is missing the ACP band A4, which is diagnostic for $R$. laevigata and is present in the other three $R$. banksiae $\times R$. laevigata hybrids (Table 1 ). Rosa $\times$ fortuniana was brought from China about 1850 by Robert Fortune and was deduced to be a natural hybrid between $R$. banksiae and $R$. laevigata (Harkness, 1978) from the morphological characteristics. One possibility is that it is a second generation derivative of this hybrid, although given its sterility, this is not likely. The most probable explanation of this inconsistency of the isozyme data, given the morphological similarity of $R$. xfortuniana to the three other hybrids, is that the three specimens of $R$. laevigata assayed did not represent the range of isozyme alleles present for ACP within this species.

Rosa $\times$ manetii Crivelli is a widely grown rootstock with a poorly known background. It is frequently stated to be a noisette rose $(R$. chinensis $\times R$. moschata) and has been previously named as $R$. $\times$ noisettiana manetii hort. The isozyme phenotype is consistent with the $R$. chinensis parentage, but the lack of ACP band A3 is inconsistent with $R$. moschata parentage. In addition, four MDH-2 bands (M8, M9, M10, M11) are not found in either parent, suggesting that another species is involved in its parentage or that a wider range of accessions needs to be assayed for isozyme 
Table 1. Isozyme phenotypes of Rosa spp. and some putative hybrids.

\begin{tabular}{|c|c|c|c|c|c|}
\hline \multirow[b]{3}{*}{ Accession } & \multicolumn{5}{|c|}{ Bands detected } \\
\hline & \multicolumn{5}{|c|}{ Isozymes } \\
\hline & $\mathrm{ACP}$ & MDH-1 & MDH-2 & PGI- $2^{z}$ & Comments $^{y}$ \\
\hline \multicolumn{6}{|l|}{ Parents } \\
\hline banksiae $(8)^{\mathrm{x}}$ & 2 & 3 & 7 & $7,9,11$, or 7 & --- \\
\hline bracteata (3) & 5 & 3 & 9 & 7 & --- \\
\hline brunonii (2) & 2 & 3 & 7 & $7,9,11$, or 9 & --- \\
\hline chinensis (8) & 2 & $\begin{array}{c}1,2,3, \text { or } 3 \\
\text { or } 3,4,5\end{array}$ & 7 & 7 & --- \\
\hline foliolosa (1) & 3 & 3 & 11 & 7 & --- \\
\hline laevigata (3) & 4 & 3 & 7 & 9 & --- \\
\hline moschata (5) & 3 & 3 & 7 & $\begin{array}{l}7 \text { or } 9 \\
\text { or } 7,8,9 \\
\text { or } 7,9,11\end{array}$ & --- \\
\hline$\times \operatorname{odorata}^{\mathrm{w}}(1)$ & 2 & 3 & 7 & 7 & --- \\
\hline roxburghii (3) & 3 or 5 & 3 & 9 & 7 & --- \\
\hline rugosa (11) & 1 or 2 & 3 or $3,4,5$ & $\begin{array}{l}7,8,9 \text { or } \\
9 \text { or } 8,9 \text { or } \\
7,8,9,10,11\end{array}$ & 7 & --- \\
\hline setigera (5) & 2 & 3 & 7 & 9 or 6,7 & --- \\
\hline wichuraiana (6) & 1 or 3 & 3 & 7 & 7 & --- \\
\hline \multicolumn{6}{|l|}{ Hybrids $^{\mathrm{v}}$} \\
\hline \multicolumn{6}{|l|}{$\times$ fortuniana } \\
\hline (bank $\times$ laev $)$ & 2 & 3 & 7 & $7,8,9$ & (A4) \\
\hline 86-3 (bank x laev) & 2,4 & 3 & 7 & $7,8,9$ & Consistent \\
\hline $18-24($ bank $\times$ laev $)$ & 2,4 & 3 & 7 & $7,8,9$ & Consistent \\
\hline Basye rootstock & & & & & \\
\hline (bank $\times$ laev) & 2,4 & 3 & 7 & $7,8,9$ & Consistent \\
\hline Mermaid (brac $\times$ odor) & 5 & $1,2,3$ & $7,8,9$ & 7 & (A2) \\
\hline $\begin{array}{l}\times \text { manetii }(\text { chin } \times \text { mosc }) \\
\text { (A3) }\end{array}$ & 2 & $3,4,5$ & $7,8,9,10,11$ & $7,8,9$ & M8, M9, M10, M11 \\
\hline$\times$ calocarpa $($ chin $\times$ rugo $)$ & 2 & 3 & $9,10,11$ & 7 & M10, M11, (M7) \\
\hline \multicolumn{6}{|l|}{ Basye's Purple } \\
\hline$($ foli $\times$ rugo $)$ & 1,3 & 3 & 11 & 6,7 & I6 \\
\hline 84-1000 (laev $\times$ roxb) & 3,4 & 3 & $7,8,9$ & $7,8,9$ & Consistent \\
\hline $90-300($ seti $\times$ wich $)$ & 2,3 & 3 & 7 & $7,8,9$ & Consistent \\
\hline 90-1 (wich $\times$ bank) & 2,3 & 3 & 7 & $7,9,11$ & Consistent \\
\hline 90-2 (wich $\times$ bank $)$ & 2,3 & 3 & 7 & 7 & Consistent \\
\hline \multicolumn{6}{|l|}{$\begin{array}{l}\text { Silver Moon } \\
\quad[(\text { wich } \times \text { Devoniensis })\end{array}$} \\
\hline $\mathrm{x}$ laev] & 1,2 & $1,2,3$ & $1,2,7$ & 7 & A4, I9) \\
\hline $19-51$ (wich $\times$ laev $)$ & 2 & 3 & 7 & $7,8,9$ & (A4, A3 or A1) \\
\hline 89-1 (wich $\times$ roxb) & 1,3 & 3 & $7,8,9$ & 7 & Consistent \\
\hline 88-1 (wich $\times$ rugo $)$ & 2,3 & 3 & $7,8,9$ & 7 & Consistent \\
\hline 88-3 (wich $\times$ rugo $)$ & $\overrightarrow{1}$ & 3 & $7,8,9$ & 7 & Consistent \\
\hline 86-7 (wich $\times$ rugo) & 2,3 & 3 & $7,8,9$ & 7 & Consistent \\
\hline $19-39$ (wich $\times$ rugo $)$ & $\overrightarrow{1}$ & 3 & $7,8,9$ & 7 & Consistent \\
\hline $19-50$ (wich $\times$ rugo $)$ & 2,3 & 3 & $7,8,9$ & 7 & Consistent \\
\hline $19-55$ (wich $\times$ rugo) & 1 & 3 & $7,8,9$ & 7 & Consistent \\
\hline 19-109 (wich $\times$ rugo $)$ & 1 & 3 & $7,8,9$ & 7 & Consistent \\
\hline Max Graf (wich $\times$ rugo) & 1 & 3 & $7,8,9$ & 7 & Consistent \\
\hline
\end{tabular}

${ }^{2}$ PGI-1 was monomorphic for I3.

${ }^{y}$ Extra bands (missing bands), consistent $=$ phenotype consistent with parentage in column 1.

${ }^{x}$ Numbers in the parentheses are the number of accessions assayed.

${ }^{w} R o s a \times o d o r a t a$ is thought to be an interspecific hybrid between $R$. chinensis and $R$. gigantea.

${ }^{\vee}$ banksiae $=$ bank $;$ laevigata $=$ laev $;$ bracteat $a=$ brac $;$ odorata $=$ odor $;$ chinensis $=$ chin $;$ moschata $=$ mosc $;$ rugosa $=$ rugo $;$ foliolos $a=$ foli , roxburghii $=$ roxb; setigera $=$ seti $;$ wichuraiana $=$ wich.

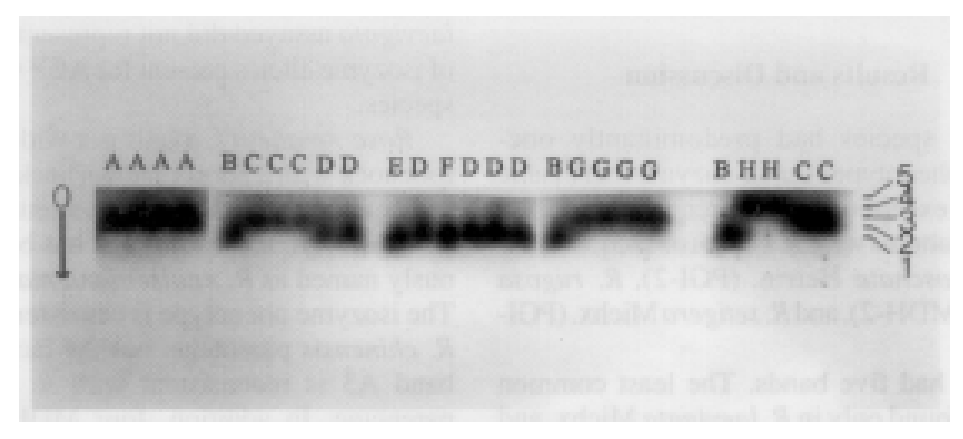

Fig. 1. Acid phosphatase polymorphisms of rose species and hybrids as run on a morpholine citrate $(\mathrm{pH} 6.1)$ gel system. The letters represent the following band phenotypes: $A=A 4, A 3 ; B=A 2 ; C=A 3 ; D=A 3$, $\mathrm{A} 2 ; \mathrm{E}=\mathrm{A} 1 ; \mathrm{F}=\mathrm{A} 2, \mathrm{~A} 1 ; \mathrm{G}=\mathrm{A} 4$ and $\mathrm{H}=\mathrm{A} 5$. polymorphisms. The five-banded pattern in MDH-2 is consistent with its tetraploidy.

Rosa $\times$ calocarpa Willm. had its origin before 1891 and its parentage is described as $R$. rugosa $\mathrm{x}$ a form of $R$. chinensis (Cairns, $1993)$. The $R$. rugosa parentage is evident in its very rugose leaves and very prickly stems. In addition, the isozyme phenotype is consistent with this parentage. The male parent is stated to be a form of $R$. chinensis that could include $R$. chinensis or any of its many hybrid cultivated forms. The MDH-2 phenotype of the hybrid has the M7 band of $R$. chinensis, which suggests that the pollen parent is probably a hybrid of $R$. chinensis.

Unfortunately, the parentage of many roses are speculative based on recollection and morphological characteristics. Of the five clones that we examined, the reported parentage of two (Basye rootstock, 'Max Graf') was consistent with their isozyme phenotypes, whereas three cultivars ('Mermaid', 'Basye's Purple', and 'Silver Moon') were inconsistent (Table $1)$.

'Basye's Purple' parentage is reported as a cross between $R$. foliolosa Torr. \& Gray and $R$. rugosa rubra (Verrier, 1992). Morphologically, it is intermediate between its parents and its $\mathrm{ACP}$ and $\mathrm{MDH}$ phenotypes are consistent with its parentage, but it has a PGI-2 band (I6) not present in either parent. Only one $R$. foliolosa was available, so it is quite possible that further work would reveal the presence of this band.

'Mermaid' is reportedly from a cross between $R$. bracteata Wendl. and a double yellow tea rose, perhaps 'Mme de Tartas' (Cairns, 1993; Harkness, 1978). The isozyme phenotype clearly reflects its $R$. bracteata parentage with the ACP band A5 and the MDH-2 band M9 and its $R$. chinensis/R. ×odorata parentage with its MDH-1 (M1, M2, M3) phenotype. The only inconsistency is the lack of the ACP band A2, which is expected from the $R$. chinensis/R. ×odorata parentage. Further screening of double yellow tea roses, especially 'Mme de Tartas' needs to be done to confirm this reported parentage.

'Silver Moon' reported parentage varies from ( $R$. wichuraiana $\times$ 'Devoniensis') $\times R$. laevigata to $R$. laevigata $\mathrm{x}$ (unknown $R$. wichuraiana hybrid from Van Fleet) to $R$. wichuraiana $\times$ R. laevigata (Cairns, 1993; Harkness, 1978). Its MDH-2 isozyme phenotype indicates it has some $R$. chinensis background (from 'Devoniensis' grandparent) and the ACP phenotype is consistent with both a $R$. wichuraiana and $R$. chinensis parentage, but the bands expected from a $R$. laevigata parentage (ACP, A4; PGI-2, I9) are not present. Although this result casts doubt on the reported $R$. laevigata parent, given the small number of $R$. laevigata clones examined, further work needs to be done to verify this.

Isozymes are an excellent tool to confirm parentage of interspecific hybrids when the parents are known and differ with respect to the bands at the assayed loci. Among the materials assayed, ACP was the most diagnostic isozyme for hybrid rose verification, although in specific cases, MDH and PGI also 


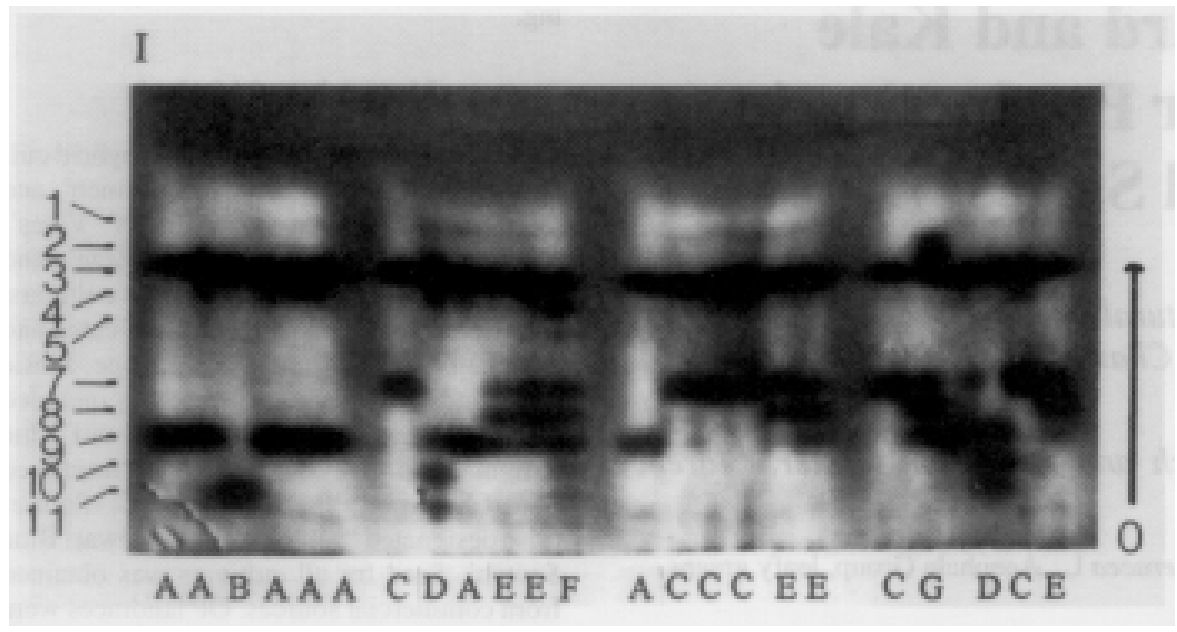

Fig. 2. Malate dehydrogenase polymorphisms of rose species and hybrids as run on a morpholine citrate $(\mathrm{pH}$ 6.1) gel system. The letters represent the following $\mathrm{MDH}-1 / \mathrm{MDH} 2$ band phenotypes: $\mathrm{A}=\mathrm{M} 3 / \mathrm{M} 9$; B = M3/M11; C = M3/M7; D = M3/M9, M10, M11; E=M3/M7, M8, M9; F = M3, M4, M5/M7, M8, M9, M10, M11; G = M1, M2, M3/M7, M8, M9.

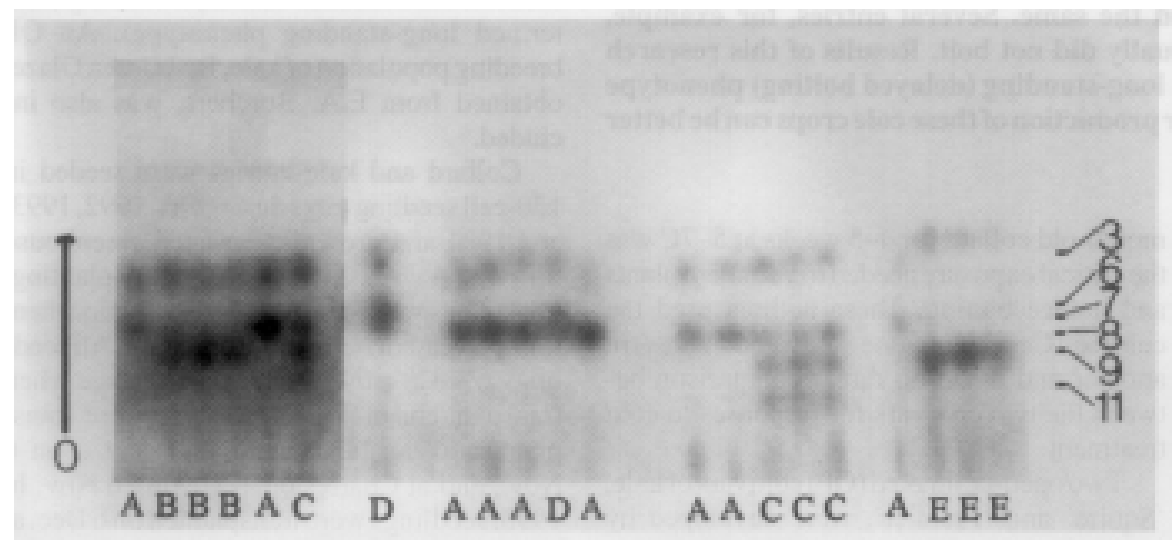

Fig. 3. Phosphoglucose isomerase polymorphisms of rose species and hybrids as run on a lithium borate $(\mathrm{pH}$ 8.3) gel system. The letters represent the following PGI-1/PGI-2 band phenotypes. $\mathrm{A}=\mathrm{I} 3 / \mathrm{I} 7$; $\mathrm{B}=\mathrm{I} 3 / \mathrm{I} 7$, $\mathrm{I} 8, \mathrm{I} 9 ; \mathrm{C}=\mathrm{I} 3 / \mathrm{I} 7, \mathrm{I} 9, \mathrm{I} 11 ; \mathrm{D}=\mathrm{I} 3 / \mathrm{I} 6, \mathrm{I} 7 ; \mathrm{E}=\mathrm{I} 3 / \mathrm{I} 9$. were useful. The ability of using isozyme phenotypes to analyze the reported species parentage of other roses is limited by the number of generations since the cross was made and the number of accessions of the species involved that have been assayed.

\section{Literature Cited}

Byrne, D.H. and T.G. Littleton. 1988. Electrophoretic characterization of diploid plums of the Southeastern United States. J. Amer. Soc. Hort. Sci. 113:918-924.

Byrne, D.H. and G. Littleton. 1989. Interspecific hybrid verification of plum $X$ apricot hybrids via isozyme analyses. HortScience 24:132-134.

Cairns, T. (ed.). 1993. Modern roses 10: The comprehensive list of roses of historical and botanical importance. Amer. Rose Soc., Shreveport, La.

Harkness, J. 1978. Roses. J.M. Dent \& Sons, London.

Hubbard, M., J. Kelly, S. Rajapakse, and R. Ballard. 1992. Restriction fragment length polymorphisms in rose and their use for cultivar identification. HortScience 27:172-173.

Kim, Y. 1994. Phylogenetic studies of selected species of Rosa. MS Thesis, Texas A\&M Univ., College Station.

Kuhns, L.J. and T.A. Fretz. 1978. Distinguishing rose cultivars by polyacrylamide gel electrophoresis. II. Isozyme variation among cultivars. J. Amer. Soc. Hort. Sci. 103:509-516.

Parfitt, D.E., S. Arulsekar, and D.W. Ramming. 1985. Identification of plum $x$ peach hybrids by isozyme analysis. HortScience 20:246-248.

Torres, A.M., T. Milan, and J.I. Cubero. 1993. Identifying rose cultivars using random amplified polymorphic DNA markers. HortScience 28:333-334.

Vainstein, A. and H. Ben-Meir. 1994. DNA fingerprint analysis of roses. J. Amer. Soc. Hort. Sci. 119:1099-1103.

Verrier, S. 1991. Rosa rugosa. Capability's Books, Deer Park, Wis.

Yoneda, K. et al. 1993. Identification of rose species and hybrids by leaf peroxidase isozyme phenotypes. Bul. College Agr. Vet. Med., Nihon Univ. 50:22-25. 